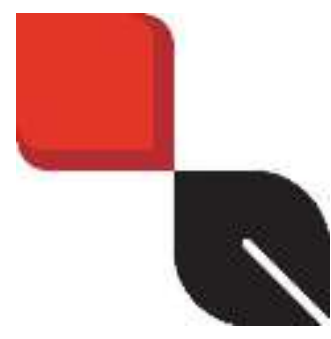

Cuadernos del CILHA n 34 - 2021 | publicación continua

ISSN 1515-6125 | EISSN 1852-9615

https://revistas.uncu.edu.ar/ojs3/index.php/cilha

CC BY-NC 2.5 AR

Recibido: 14/05/2021 Aprobado: 10/06/2021 |

PP. 1-16

DOI: https://doi.org/10.48162/rev.34.008

\title{
El narcotráfico como dispositivo de poder sexo-genérico y el engañoso empoderamiento femenino, en Perra Brava
}

Drug Trafficking as a Sex-Generic Power Device and Deceptive Female Empowerment, in Perra Brava

Magela Baudoin

Dhttps://orcid.org/0000-0002-4908-8053

University of Oregon mbaudoin@uoregon.edu

Estados Unidos

Resumen: Utilizando los aparatos teóricos de Giorgio Agamben y de Sayak Valencia, en el presente trabajo demuestro que el narcotráfico actúa en la novela Perra Brava de Orfa Alarcón como un dispositivo de poder sexo-genérico e induce a la reproducción de masculinidades endriagas, las mismas que reafirman un sistema necropolítico, heteropatriarcal y violento. Esto explica que la heroína, Fernanda Salas, al transformarse en un sujeto endriago y alcanzar la cima de la organización criminal no se libere ni subvierta el sistema que la oprime sino que lo retroalimenta, con lo cual asistimos a su resurrección o renacimiento fallido. 
El narcotráfico como dispositivo de poder sexo-genérico y el engañoso empoderamiento femenino, en Perra Brava

Palabras clave: Dispositivo de poder, Capitalismo gore, Necropolítica, Endriago.

\begin{abstract}
Using the theoretical apparatuses of Giorgio Agamben and Sayak Valencia, in the present work I show that drug trafficking acts in the novel Perra Brava by Orfa Alarcón as a sex-generic power device and induces the reproduction of "endriagas masculinities" that reaffirm a system necropolitical, heteropatriarchal and violent. This explains why the heroine, Fernanda Salas, by transforming herself into an "endriago subject" and reaching the top of the criminal organization is not liberating or subverting the system that oppresses her, but rather giving it feedback, thereby witnessing her failed resurrection or rebirth.
\end{abstract}

Keywords: Power device, Gore capitalism, Necropolitics, Endriago.

De entre todas las protagonistas de la llamada narcocultura ${ }^{1}$, probablemente Fernanda Salas sea una de las más complejas y controversiales. No se trata de la mujer-objeto sumisa y descartable de buena parte de las novelas del género; o no lo es, exclusivamente. Pero tampoco estamos ante esos personajes independientes y justicieros que evocan algunos narcocorridos míticos de "Los tigres del norte" u otros grupos de música popular, como Camelia, la tejana o La reina del Sur², ambas llevadas a la televisión. Fernanda, la heroína de Perra Brava (Alarcón, 2010) es más difícil de leer, precisamente porque la apoteosis de violencia de su transformación final puede encandilar y hacernos leer como emancipación algo que, si se ve con cuidado, en realidad no lo es.

El presente ensayo analiza, desde las nociones de "dispositivo de poder" de Giorgio Agamben y de "capitalismo gore" de Sayak Valencia, la apropiación de comportamientos masculinos-endriagos por parte de personajes femeninos de la literatura, ubicados en entornos patriarcales violentos y signados por la necropolítica (Mbembe) del narcotráfico. Se estudia para ello la metamorfosis de Fernanda Salas, que

\footnotetext{
${ }^{1}$ De acuerdo con Sánchez (2009) la narcocultura apareció en las postrimerías de 1970 en algunas localidades sinaloenses. Desde finales de la década de 1990 del siglo XX se ha estudiado en sus diferentes expresiones: música, cine, religiosidad, arquitectura, vestimenta, etcétera (Astorga 1995, 1997; Campbell, 2005; Cantarell, 2002; Cervantes, 2002; Córdova 2012; De la Torre, 2002; Fernández, 2001; Galindo, 2002; González, 1996; Mendoza, 2005; Valenzuela, 2002)" (Núñez y Espinoza, 2017).

${ }^{2}$ Este narcocorrido y la serie de televisión se basan en la novela homónima de Arturo Pérez Reverte.
}

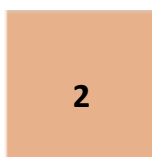

Cuadernos del CILHA n $34-2021$ 
pasa de un estado de fascinación y sumisión sadomasoquista a un jefe sicario, que la tortura y esclaviza, a uno de insubordinación y dominación absoluta del hombre, donde se invierten los términos de la relación. Este empoderamiento, sin embargo - he aquí la premisa de este trabajo-, no implica una puesta en cuestión de las estructuras de dominación del sistema patriarcal sino la retroalimentación de este.

\section{Un personaje con agencia}

La protagonista de Perra brava es una muchacha universitaria, de familia acomodada que se obsesiona con un jefe sicario llamado Julio Cortés y termina involucrada en una relación amorosa con él. No se trata de una joven engañada ni de la clásica "buchona" (Castellanos, 2018, p. 502). Se entiende por buchonas a las esposas, amantes o acompañantes de los narcotraficantes, que normalmente provienen de estratos sociales bajos y que hallan en ellos un modo de remontar la pobreza y de ascenso social. Comparten un código estético: ostentación de lujo, modos de vestir extravagante, maquillajes elaborados, múltiples cirugías plásticas (pechos, glúteos, rostro), exuberantes uñas largas, etc. El término se usa principalmente en los estados del norte de México como Tamaulipas, Jalisco, Baja California y Sinaloa (TV Azteca, 2021, en línea).

He aquí una primera diferencia entre la imagen estereotipada de la mujer del narco y este perfil que no tiene necesidad económica ni social de hacerlo: “...Yo sí tengo estilo, yo si tengo lana, yo si tengo nombre: me llamo Fernanda Salas y no tengo que andar alardeando nada porque lo que soy se evidencia" (Alarcón, 2010, p. 32). Ella sabe en el mundo en que se está metiendo. Fernanda no es seducida, no es embaucada, entra en la relación al tanto de la condición delictiva de Julio; aún así, lo desea, lo busca, lo conquista y permanece en una relación violenta, aunque eventualmente tiene ocasión de liberarse de ella. Esta agencia puede observarse en varias oportunidades, como en el siguiente fragmento:

Cómo no codiciarlo. Mara llegó al antro con la frente tan alta y la mirada tan despectiva, como si estuviera manejando un BMW, como si portara la novedad Tous antes de que saliera al mercado, o como si fuera del brazo del mismísimo 
Orlando Bloom. No era para menos... Es que cómo no iba a codiciarlo, si era el hombre más hermoso que yo había visto y vería alguna vez en mi puta vida. -Qué, ¿te gustó mi chico? - me preguntó mirándome a través del reflejo, porque no tuvo el valor de mirarme directamente.

- Claro, cómo no me va a gustar.

Mara había atravesado el asqueroso pasillo del brazo de Julio. Era como si lo arrastrara. En cuanto lo vi supe que me jugaría hasta las pestañas postizas con tal de conseguirlo. (Alarcón, 2010, pp. 14-15)

La voz en primera elegida por Alarcón no deja duda sobre los deseos del personaje. Fernanda manifiesta a la pareja del sicario (Mara) que le gusta ese hombre y deja claramente establecido que irá por él. Asimismo, nos advierte por las marcas de lujo que menciona y por la alusión al actor de Hollywood, Orlando Bloom, que no solo hay una atracción sexual, sino un reconocimiento simbólico del espacio de consumo que posibilita el sicario y que ella lee perfectamente e identifica como propio.

\section{Dispositivo de poder}

En la novela se observa cómo el narcotráfico es un "dispositivo de poder sexo-genérico" que produce subjetividades, valores, prácticas, identidades en arreglo a "parámetros heteronormativos o androcéntricos" (Núñez y Espinoza, 2017). Sin embargo, antes de profundizar esta definición conviene detenerse en el trabajo de Giorgio Agamben, quien (tomando como punto de partida a Foucault³) llama dispositivo "a cualquier cosa que de algún modo tenga la capacidad de capturar, orientar, determinar, interceptar, modelar, controlar y asegurar los gestos, las conductas, las opiniones y los discursos de los seres vivientes" (Agamben, 2015, p. 23). Esto implica que un dispositivo - por ejemplo, la filosofía, la ciencia, la cultura pop, la propaganda política, la publicidad, las instituciones, la religión, el lenguaje mismo, la narcocultura - puede incidir, influir y/o generar subjetividades. Si consideramos nuevamente la propuesta de Guillermo Núñez Noriega y de Claudia Espinoza, entenderemos que el narcotráfico actúa como un dispositivo que reproduce reglas y patrones de género y de sexualidad que conforman

\footnotetext{
${ }^{3}$ Michel Foucault definió como "dispositivo" a un "conjunto de estrategias de relaciones de fuerza que condicionan ciertos tipos de saber y son condicionados por él” (Agamben, 2015, p. 10).
} 
un sistema de dominación patriarcal y heteronormativo, que se sustenta en la supremacía masculina.

El narcotráfico como una de las modalidades del crimen organizado y su narcocultura, involucra individuos, subjetividades, prácticas, relaciones, valores, concepciones, actitudes, rituales y rutinas, objetos, significados, así como una vasta producción cultural. Pero, ¿de qué envergadura es la relación de la organización criminal del narcotráfico, con todos los componentes que la conforman, y la reproducción del sistema sexo-género? La respuesta que ofrecemos es que resulta total, estructurante, fundamental, y que de ninguna manera se trata de una relación superficial, circunstancial o anecdótica. (Núñez y Espinoza, 2017, en línea)

Los autores ofrecen evidencia empírica que demuestra que el narcotráfico, con toda su producción cultural (narcocultura) y necroprácticas ${ }^{4}$, es un dispositivo de poder complejo que, instalado en un sistema capitalista gore ${ }^{5}$ (Valencia, 2010), produce sujetos hetero/patriarcales/hiperviolentos (Núñez y Espinoza, 2017, en línea); es decir, sujetos (mujeres y hombres) que interiorizan y reproducen patrones de obediencia a las masculinidad hegemónica, violenta, capitalista y heteronormativa que le da sostén al sistema. Este aspecto es evidente a lo largo de toda la novela, en la que Fernanda se somete, primero, y adopta, después, conductas típicas del prototipo de macho/jefe/violento del narcotráfico. A continuación, se muestran dos situaciones específicas que pueden leerse como hechos concatenados: la primera, al inicio de la novela, cuando Fernanda está aún en condición de esclavitud; y, la segunda, en la que

\footnotetext{
${ }^{4}$ Según Sayak Valencia las "necroprácticas" son todas aquellas acciones y tecnologías del asesinato radicales desarrolladas por los narcoemprendedores endriagos (p. 147).

${ }^{5}$ En el capitalismo gore es definido por Valencia como un sistema en el que la producción de mercancías propio del capitalismo se sustituye por la destrucción del cuerpo humano, que se convierte en el "producto" o "mercancía". De esta manera, "la fuerza del trabajo se sustituye por medio de prácticas gore, entendidas como el ejercicio sistemático y repetido de la violencia más explícita para producir capital” (Valencia, 2010, p. 51). Algunas de las razones que explican el capitalismo gore son la pauperización del trabajo, el desprecio por la clase obrera, el crecimiento desaforado de la pobreza, la frustración del hiperconsumismo y la espectacularización de la delincuencia. Violencia y prácticas delictivas ya no son concebidas como vías éticamente distópicas sino como "estrategias al alcance de todos" para gestionar el uso de la violencia como herramienta para hacerse de dinero (p. 52).
}

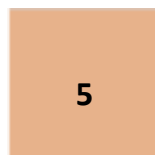

Cuadernos del CILHA n $34-2021$ 
ya ha ganado el afecto del capo y, por tanto, poder, que ella ejerce con acciones igualmente violentas y sádicas contra terceros. Véase la primera:

Supe que con una mano podría matarme. Me había sujetado el cuello, su cuerpo me oprimía en la oscuridad. Había atravesado la casa sin encender ninguna luz ni hacer ruido. No me asustó porque siempre llegaba sin avisar: dueño y señor. Puso su mano sobre mi boca y dijo algo que no alcancé a entender. No pude preguntar. El comenzó a morderme los senos y me sujetó ambos brazos, como si yo fuera a resistirme.

Nunca me opuse a esa clase de juegos. Me excitan las situaciones de poder en las que hay un sometido y un agresor. Me excitaba todavía más entender que para él no eran simplemente juegos sexuales: Julio doblegaba mi mente, mi cuerpo, mi voluntad absoluta. (Alarcón, 2010, p. 11)

El acto sexual se desarrolla hasta el punto en que Julio le ordena a Fernanda que le haga una felación y lama todo su cuerpo cubierto de sangre, sangre de un hombre asesinado por él: "Para que te lo sepas traes encima sangre de un cabrón con muchos huevos, y con todo y todo se lo cargó la chingada porque la vida se gana a chutazos" (Alarcón, 2010, pp. 12-13). Ella padece fobia a la sangre (hemofobia) por lo que él la tortura y la "domestica" con la orden. "Para que se te quite lo fresita" (p. 11), le dice. Con el calificativo "fresita" ("quisquillosa”, "melindrosa”, “delicada”, "niña bien”, "rica”), el sicario marca no solo una cuestión de carácter sino de clase; él, una masculinidad marginalizada y empoderada, está sometiendo a una mujer y, al mismo tiempo, a una clase. Su subjetividad endriaga ejemplariza con la sangre de un cuerpo muerto y vencido. Así, la muerte actúa como un "dispositivo de poder sexo-genérico", que sienta soberanía, en los términos de Achille Mbembe ${ }^{6}$ :

sovereignty resides, to a large degree, in the power and the capacity to dictate who may live and who must die. Hence, to kill or to allow to live constitute the limits of sovereignty, its fundamental attributes. To exercise sovereignty is to exercise control over mortality and to define life as the deployment and manifestation of power. (Mbembe, 2003, p. 11) 
Julio tiene el poder de decidir quién muere y quién no. Él, que encarna el poder masculino, ha asesinado a un hombre y con su sangre adoctrina y esclaviza a Fernanda. "Si no obedeces, serás la próxima", parece advertirle. Por otra parte, ella recibe la violencia y la consiente ("Nunca me opuse a esa clase de juegos. Me excitan las situaciones de poder en las que hay un sometido y un agresor"), con lo cual hace parte esencial del mantenimiento del sistema. Un sistema del que es víctima desde la niñez, con un padre violento que ha asesinado a la madre, luego de sistemáticos ejercicios de violencia:

La hemofobia también tiene otras connotaciones, debido a que se originó en un episodio de violencia doméstica en la familia de Fernanda. Cuando ella tenía seis años, su padre asesinó a su madre, y ella quedó atrapada debajo del cuerpo de su madre hasta que su hermana la rescató (Alarcón, 2010, p. 26). Debido a este crimen, la misma novela establece la idea de que Fernanda está con Julio porque él representa y continúa la violencia paterna. (Castellanos, 2018, p. 504)

Hago un paréntesis en este punto para llamar la atención sobre la figura del padre, este otro hombre violento y asesino. Contradictoria en sus sentimientos, Fernanda manifiesta durante la novela preocupación, ¿afecto?, por él y también terror por su retorno. Confiesa que ha llorado su partida, que incluso lo extraña y se apiada de su soledad. Lo echa en falta hasta que empieza a soñar con la hermana "ahogada en sangre" y entonces aparece "el miedo a que él volviera". Ante lo cual, dice la protagonista: “...comencé a necesitar a un hombre, a muchos hombres, hasta encontrar el que fuera capaz de, por sí solo, cuidar a mi hermana y tratarme a mí como una princesa" (Alarcon, 2010, p. 64). Como se ve, Fernanda Salas teme por su vida y por la de su familia y clama por protección. De algún modo, estar bajo el dominio, pertenecer y ser la protegida del sicario, alivia sus miedos atávicos y justifica la violencia recibida. "En contra de ese cabrón no había voz, no había ley, no había voluntad. A los pies de ese cabrón yo había dejado mi vida para que la pateara cuando quisiera" (Alarcón, 2010, p. 24). Hay entonces una operación de sustitución (Torres y Saavedra, 2019). El sicario es ese padre temido y ejemplarizante.

Es interesante notar que Fernanda asimila y reproduce este sistema de valores incluso cuando la relación de dominación con Julio se modifica y él le propone matrimonio, con lo cual la "princesa" cuenta con la movilidad física y los recursos económicos para 
escapar y liberarse. De hecho, su hermana le plantea fugarse y ella prefiere quedarse gozando de los beneficios del consumo al que está habituada (indumentaria de alta moda, autos de hiperlujo, armas, droga...). Al contrario, progresivamente va apropiando los códigos de venganza del sicariato y el comportamiento de Julio, como jefe máximo, con niveles de crueldad insospechados. En el capítulo 61, he aquí el segundo ejemplo anunciado previamente, sale a "patrullar" con el Yeyo (guardaespaldas y amante) las colonias (narcoterritorio) sobre las que tiene control Julio. Divisa en el patio de una de las casas su ropa ("un saco de Zara gris", una playera, "un vestido negro Louis Vuitton") y comienza a llenarse de furia por la traición ("Nadie me explicó nada, pero para mí no había más que la tipa se acostaba con mi hombre y en mi propia casa"). Le ordena al chofer parar, se baja y emprende a patadas contra la mujer, que está embarazada.

-iDefiéndete, pendeja! -le grité.

No sé como la jalé, pero al tenerla en el piso apenas alcancé a patearla una vez en el estómago cuando sentí que el cuerpo no me respondía, pero no era nada, era solo que mi fuerza era estorbada por cinco Cabrones que me separaban de la vieja esa. (Alarcón, 2010, p. 163)

El episodio promete desencadenar en una guerra entre pandillas y despertar la furia del sicario. El Yeyo, en su condición de subalterno, espera lo peor y Fernanda reacciona como un soldado sicario, dispuesto a morir y a matar por poder (un poder sustentado, precisamente, en la capacidad de suprimir vidas humanas y que la hace soberana):

- Nos va a torcer a todos, Chingada madre, nos va a torcer a todos - sudaba el Yeyo, hablaba solo, se mordía los labios, le temblaban las manos.

Pues que me mate, pensé. Que me mate con una sola mano. Si tanto le importa una puta arrabalera, que me mate. Que vuelva a ser él. Que se le trabe la quijada en mis costillas, que me mate. (p. 164)

En esta escena se muestra nuevamente la forma en que el narcotráfico opera como un dispositivo de poder sexo-genérico. Fernanda ha devenido en un sujeto endriago, término acuñado por Sayak Valencia y que explicaré más adelante. Ha aprendido las lecciones del maestro y las ha aplicado como una alumna aventajada. Está dispuesta a doblegarse sola ante él. Ha ascendido en la pirámide de la organización y ese salto impresionante se debe a su nuevo comportamiento. "Iba a comenzar a llorar y eso fue 
lo que más rabia me dio. Ante Julio yo quería arrodillarme, pero ante los demás no. No me dejaría humillar por nadie más. Uno tenía que demostrar de quién era el poder" (Alarcón, 2010, p. 164).

\section{El narco-Estado}

Qué ocasiona la metamorfosis de Fernanda, cuál es el detonante que posibilita su escalada. Volvamos a la primera parte de la novela, al momento en que la policía detiene el auto de Fernanda y encuentra en él la cabeza de un cadáver que ha sido dejada para tenderle una trampa a Julio. Ella se inculpa, se "inmola" (Alarcón, 2010, p. 74) para protegerlo. Al atribuirse el asesinato, Fernanda evidencia su lealtad al sicario que, al rescatarla, modifica los términos de la relación y la "asciende" en su mapa afectivo. Fernanda ya no será una amante más, una "fresita", una "pinche vieja" o una "buchona" sino "su" mujer: la "princesa" o incluso la "reina", una nueva "jefa", debajo del jefe sicario, pero encima de todo lo demás. Julio ve en ella a un par (Castellanos, 2018, p. 500), a alguien de su misma estirpe, de su "raza", que lo merece. Ella, por su parte, comprende muy pronto esta situación:

Nada me pasaría mientras estuviera con Julio. Nunca. En esta pinche ciudad de mierda, donde hay muertos a diario, donde los enfrentamientos entre militares y policías no respetan ni a las mujeres ni a los niños que vayan pasando, yo era la mujer más protegida. La más cara. Julio me cuidaba como a su propiedad más importante, yo no tenía nada que temer. Sobre mí estaba Julio. Y sobre Julio no había ley. (Alarcón, 2010, p. 88)

La novela muestra las características de un sistema necropolítico, que funciona al margen de la ley y que contrasta con la biopolítica del poder estatal, que supuestamente debe funcionar en el ámbito de la legalidad. Ambos poderes coexisten, solo que con propósitos contrapuestos: las organizaciones criminales del narcotráfico buscan preservar su derecho a matar, sembrando el pánico; mientras el Estado busca normativizar la sociedad, preservando para ello la vida (aunque en este caso también participa activamente del otro lado). Se describe entonces un narco-Estado, en el que los políticos y la policía están implicados en el negocio ilícito de la droga y de la muerte. 
El narcotráfico como dispositivo de poder sexo-genérico y el engañoso empoderamiento femenino, en Perra Brava

Es el alcalde7, quien protege a Fernanda de la policía, la acoge en su casa para devolverla al sicario, con quien sostiene negocios ilegales.

\section{Subjetividad endriaga}

En el contexto de violencia extrema que plantea la novela, se ha discutido mucho sobre la transformación de Fernanda Salas. En algunas de esas interpretaciones se entiende que el despertar a la criminalidad del personaje es un signo de liberación. Autores como Cecilia López Badano y Silvia Ruiz Tresgallo señalan que Fernanda es "una mujer resemantizada como sujeto activo e ingobernable que acaba por transformarse en un endriago capaz de atacar los cimientos patriarcales del sistema neoliberal" (p. 210). Pero, ¿es realmente un sujeto "activo e ingobernable" que ataca los cimientos patriarcales? Discrepo de esta interpretación pues la albúmina de ferocidad y sadismo que envuelve este cuerpo renacido en el poder, no lo cuestiona ni lo utiliza para liberarse del dominio patriarcal sino que lo reproduce para sostener sus privilegios. De hecho, Fernanda es bastante consciente de su subordinación y usufructúa del poder que deviene de ella. No le interesa subvertirla. Lo que ocurre más bien es que asimila la sicología endriaga, que es la que termina transformándola.

Sayak Valencia define a los sujetos endriagos inspirada en el personaje de Amadis de Gaula: monstruo, cruce de hombre, hidra y dragón. De gran estatura, ligereza de movimientos y condición bestial "Su fiereza es tal que la ínsula en la que habita se presenta como un paraje deshabitado, una especie de infierno terrenal al que sólo podrán acceder caballeros cuya heroicidad rondara los límites de la locura y cuya descripción se asemejara a los territorios fronterizos contemporáneos" (p. 89). A partir de esta alegoría, Valencia caracteriza a un sujeto "anómalo" que hace de la violencia extrema una forma de vida, de trabajo, de socialización y de cultura. La violencia es, por lo tanto, utilizada como herramienta de empoderamiento y adquisición de capital, en una estructura de ascenso social y económica criminal. Es un modo de "respuesta al miedo a la desvirilización que pende sobre muchos varones dada la creciente precarización laboral y su consiguiente incapacidad para erigirse, de modo legítimo, en

${ }^{7}$ Orfa Alarcón alude en su novela al alcalde de Monterrey entre 2006 y 2009, Adalberto Madero (Sánchez, 2015). 
su papel de macho proveedor" (p. 90). En este sentido, se trata de una subjetividad anclada en la masculinidad marginalizada (clases sociales subordinadas o de grupos étnicos), que interioriza los elementos estructurales de una masculinidad hegemónica, capitalista, heteropatriarcal y que entiende la disidencia de manera distópica y violenta (p. 173).

Siguiendo a Félix Guattari, Sayak Valencia sostiene que la subjetividad endriaga no se sitúa en el campo individual, sino colectivo. El individuo (femenino o masculino) consume sistemas de representación sociales que luego incorpora en su identidad. La "glorificación de la cultura criminal se instaura como un nuevo nicho de mercado para la producción y el consumo, puesto que actúa instaurando modas... Emerge la figura del mafioso/criminal como el nuevo y verdadero rockstar del siglo XXI" (p. 69). Se produce la creación de un imaginario, dentro de la lógica capitalista, en el cual la figura del narcotraficante es asociada a una imagen hipermachificada de progreso, éxito, poder, hiperconsumo y no punibilidad ante la ley.

He aquí el telón de fondo de la novela: la subjetividad endriaga, en el capitalismo gore. Fernanda está rodeada de hombres armados, que siguen las órdenes de Julio y hacen de la violencia, el asesinato y del tráfico de drogas la fuente generadora del capital, de un estilo de vida consumista y de una lógica de poder irrebatible porque opera al margen de la ley y desactivando todos los sistemas de control biopolíticos (la policía y la justicia están compradas por la organización criminal como se ha visto). Ella va apropiando los símbolos y las prácticas de esta subcultura: el uso de autos de lujo (BMW, Hummer), armas, marcas de alta costura, y productos culturales (grupos de música, por ejemplo). La "adquisición" del gusto por el narco hip hop es una muestra de ello. En un principio, Fernanda aborrece la misoginia y las letras violentas y machistas de las canciones del popular grupo Cartel ("Nunca juego, para mí esto es cosa seria, pero acabarlos es tan fácil como abrirle a tus hermanas las piernas"), que es idolatrado por Julio y sus hombres. Posteriormente, la protagonista no solo las baila en una discoteca, sino que las canta de memoria porque las ha apropiado; llega incluso a fantasear con la idea de dedicarse al hip hop y de grabar una canción con el Babo (vocalista del Cartel):

... mientras yo seguía pensando que igual y ya había una salida para mi vida: el hip hop. Podría dedicarme a la música, regresaría con Julio y buscaría al Babo 
para enseñarle que sé rimar todas sus canciones y que puedo hacer las mías propias. Babo me apadrinaría y me invitaría a grabar en Casa Babilonia, su disquera. Julio se sentiría orgulloso de mí y, obvio, pondría la lana para mis grabaciones. (Alarcón, 2010, p. 135)

En consecuencia, estamos antes un sujeto femenino que es capaz de ejercer necropoder (se ubica casi en la cima de una narco-organización y utiliza los sistemas de control de la misma para subyugar a otros); realiza necroprácticas (acciones destinadas a quitar la vida de otros) y es tanatofílica (le gusta la espectacularización de la muerte, el sadismo, la destrucción, el consumo gore). Además, tiene plena conciencia de su impunibilidad ante la ley y las instituciones del Estado.

\section{Falocentrismo}

Como he dicho antes, es evidente que la transformación y empoderamiento de Fernanda no culmina con su liberación ni con la subversión del sistema de dominación machista y heteropatriarcal propio del narcotráfico que se ha descrito antes. Al contrario, ella se incorpora al sistema e, incluso, cuando vence a Julio, en la pelea final, sigue estando subordinada a él afectivamente. Recuérdese que en el capítulo final y totalmente sumida en la subjetividad endriaga, Fernanda ha asesinado al hijo de Julio, de dos años, y él vuelve para matarla, pues es lo que se espera de la venganza sicaria; sin embargo, no puede hacerlo y termina suicidándose. En el monólogo interior entendemos que Fernanda sigue enamorada de él y que ha metabolizado aplicadamente las normas de funcionamiento de este sistema criminal (es sádica, cruel, ha ganado el respeto de la organización a base de violencia y posiblemente ocupe el lugar de Julio, después de todo), al punto de superar al maestro:

- iAhora qué hago contigo cabrona! Si te dejo con vida pierdo el respeto de mis hombres. Si te mato es peor que matarme a mí mismo. Cómo te castigo, cabrona, ¿mando a que te encajuelen a ti también? O mejor que te cojan todos. Que vengan los cabrones, que se sacien. ¿Tanta carne y tan buena para echársela a los gusanos? Mejor que se sacien primero los perros. Así como los ves con asco, como si valieran menos que tú, así como dices que apestan, van a llegar a meterte la verga. Van a partirte en dos, cabrona, van a enseñarte cómo terminan las que se creen muy reinitas. 
Yo solo quería acercarme a él. Quería morir con su imagen grabada en mis pupilas. (Alarcón, 2010, p. 203)

El concepto del "otro" es central en el Segundo sexo de Simone de Beauvoir. La filósofa francesa explicó, con ejemplos que perduran en la historia, que la noción de "mujer" es un reflejo de lo que los hombres no son. Por lo tanto, la definición mujer resulta de una relación de subordinación jerárquica. Esta construcción patriarcal del sujeto femenino se ha relacionado con las diferencias biológicas y anatómicas, en primera instancia. Como resultado, la mujer terminó siendo el "sexo débil", el "segundo sexo", el "otro", siempre medido en relación con el ideal masculino. La famosa cita: "Uno no nace, sino que se convierte en mujer" llama la atención sobre la influencia de la cultura patriarcal en la conformación del ser femenino. Para ser mujer es necesario "aprender" según los parámetros de una sociedad hecha a imagen de los hombres. En este contexto, al inicio Fernanda desempeña el papel de "mujer" que se espera de ella; luego adquiere la subjetividad endriaga, encarnando en el sujeto masculino marginal y violento, con lo cual comienza a "hablar" el mismo lenguaje de la organización.

Las ideas de Beauvoir son fundamentales para cimentar la teoría falocéntrica de Luce Irigaray. Irigaray afirma que la comparación del cuerpo femenino y masculino, basada en la presencia / ausencia del falo, ha generado una relación de sumisión. Así, lo femenino se representa como "la ausencia de", como lo que "no tiene", lo que refuerza la idea freudiana de la magnificencia del falo:

Female sexuality has always been conceptualized on the basis of masculine parameters. Thus the opposition between "masculine" clitoral activity and "feminine" vaginal passivity, an opposition which Freud - and many othersaw as stages, or alternatives in the development of a sexually

"normal" woman, seems rather too clearly required by a practice of male sexuality. For the clitoris is conceived as a little penis pleasant to masturbate so long as castration anxiety does not exist (for the boy child), and the vagina is valued for the "lodging" it offers the male organ when the forbidden hand has to find the replacement for pleasure-giving. (Irigaray, 1991, p. 350) 
El cuerpo se sexualiza en la medida en que tiene un pene, que es visible y eréctil. Por lo tanto, la superioridad masculina está directamente relacionada no solo con la presencia del falo sino con su tamaño. Al no tener un pene o tener un pene "atrofiado", las mujeres son un complemento para los hombres y deben adaptarse a la forma de ese cuerpo masculino y a la satisfacción de sus necesidades eróticas. El placer, por lo tanto, se concibe como una necesidad legítima y masculina, que gira en torno al pene. En esta sociedad falocéntrica, dice Irigaray, las mujeres son vistas como cuerpos carentes, sin sexo. En consecuencia, no hay posibilidad de disfrute, no hay libido y no hay derecho al deseo sin el falo. La idea del placer femenino ${ }^{8}$ no es admitida sin el otro masculino. Ella, al no estar "sexualizada", se convierte en la "otra" (de la que habló Beauvoir), "inferior".

En Perra brava la relación sexual gira alrededor de la satisfacción del placer de Julio y es completamente falocéntrica (ya marqué al inicio la felación). Cuando Fernanda desaparece por dos semanas y tiene encuentros sexuales con otros hombres, el recuerdo del sicario permanece vivo y la consumación del placer tiene que ver, nuevamente, con la instrumentalización del pene: "Pude lamerlo empezando en la entrepierna y terminando en el cuello... De cuclillas sobre él, por primera vez en mucho tiempo me preocupé por mi propio placer, por metérmelo y frotármelo a mi gusto" (Alarcón, 2010, p. 135) En el desenlace, este falocentrismo vuelve a aparecer. Julio amenaza con castigarla con una violación grupal de sus hombres ("van a meterte la verga") y ella responde: "A todos me los tiré, tú que les confiabas tanto, que creías que me cuidaban" (p. 203), con lo cual fulmina el amor propio del sicario que se suicida. Fernanda ha llegado a la cima y seguramente ocupará su lugar como "reina" de la organización criminal.

A pesar de ello, ¿podemos pensar en un triunfo, en una verdadera liberación? ¿Es esta apoteosis de violencia una derrota al "yugo patriarcal", como afirman autores como

\footnotetext{
8 Irigaray refuta esa idea largamente reproducida por la cultura patriarcal y señala que la mujer no tiene un sexo sino al menos dos. Que tener dos labios, en lugar de un pene, se autoerotiza todo el tiempo y es capaz de recibir placer sin la necesidad del hombre. La mujer se toca y puede alcanzar orgasmos sin la mediación del falo. "This organ (women's genital) which has nothing to show for itself also lack a form of its own. And if woman takes pleasure precisely from this incompleteness of form which allows her organ to touch itself over and over again, indefinitely, by itself, that pleasure is denied by a civilization that privileges phalomorphism" (Irigaray, 1991, p. 352).
} 
Mónica Torres Torija y Felipe Armando Saavedra, entre otros? Vuelvo a insistir en que la espectacularidad de la sangre puede confundirnos. Volvamos atrás. He señalado ya que Fernanda Salas buscaba en Julio una figura protectora que viene a ocupar el lugar del padre temido, del padre feminicida que asesinó a la madre durante la niñez. Siendo así, al empujar al sicario hacia el suicidio y convirtiéndose en la cabeza de la organización, no estaría matando al padre sino, terrible destino, convirtiéndose en él. Fernanda no ha quebrado el sistema, se ha convertido en su engranaje principal y en su esclava. Para subsistir en la organización tendrá que seguir jugando las reglas del capitalismo gore con todas sus necroprácticas y reproduciendo el sistema patriarcal que es la fibra fundamental de la organización criminal y del sistema de opresión. Como puede preverse, Fernanda será la "reina" hasta que alguien más fuerte termine con ella.

\section{Conclusión}

Tras haber revisado la novela Perra Brava de Orfa Alarcón, utilizando como marco teórico principal a Giorgio Agamben y Sayak Valencia, tenemos que el narcotráfico actúa en la novela como un dispositivo de poder sexo-genérico que se sustenta en la reproducción masculinidades endriagas que reafirman un sistema necropolítico, heteropatriarcal y violento. De este modo la protagonista de la novela, Fernanda Salas, entra en una relación de dominación/dependencia sadomasoquista con un sicario Julio Cortés - que se invierte en el devenir de la novela mas no conduce a una puesta en cuestión del sistema que la subordina sino, por el contrario, supone su asimilación a él. En consecuencia, ella adopta todas las necroprácticas propias del capitalismo gore y la subjetividad endriaga, asciende en la pirámide del narcotráfico, gana el respeto de los hombres de la organización y termina desplazando al jefe sicario, pero sigue presa del sistema, lo cual implica una resurrección o renacimiento fallido.

\section{Referencias}

Alarcón, O. (2010). Perra brava Planeta.

Agamben, G. (2015). ¿Qué es un dispositivo? seguido de El amigo y de La Iglesia y el Reino. Trad. Mercedes Ruvituso. Anagrama.

Beauvoir, S. (1991). The second sex. Random House USA Inc.

Castellanos Gonbella, C. (2018). Dinámicas de dominación y sumisión en Perra brava de Orfa Alarcón. Revista Canadiense de Estudios Hispánicos, 42, 499-520. https://www.jstor.org/stable/10.2307/26663370 
El narcotráfico como dispositivo de poder sexo-genérico y el engañoso empoderamiento femenino, en Perra Brava

Demeyer, L. (2016). Frontera, narcotráfico y género: las heroínas alternativas de la ficcionalización de la violencia en México. Anuario de Estudios Americanos, 73, 425-456.

http://estudiosamericanos.revistas.csic.es/index.php/estudiosamericanos/article/view/684/684

López-Badano, T. y Ruiz Tresgallo, S. (2017). Narconarrativas de compensaciones ficcionales (y condenas neoliberales): Yuri Herrera y Orfa Alarcón. Mitologías hoy, 14, 191-212.

https://doi.org/10.5565/rev/mitologias.389

Mbembe, A. (2003). Necropolitics (pp. 11-40). Duke University Press.

Núñez N., G. y Espinoza, C. (2017). El narcotráfico como dispositivo de poder sexo-genérico: crimen organizado, masculinidad y teoría queer. Estudios de género de EL Colegio de México, 3. https://estudiosdegenero.colmex.mx/index.php/eg/article/view/119/89

Irigaray, L. (1991). This sex which is not one. In R. R. Warhol, D. Pierce Herndl (eds.), Feminism: An Anthology of Literary Theory and Criticism, 350-356. Rutgers University Press.

Sánchez Garay, E. (2015). Ilusión mimética y punto de vista femenino en Perra brava de Orfa Alarcón. México Interdisciplinario, 4. https://www.imex-revista.com/wp-content/uploads/8_Perrabrava_Sanchez.pdf

TV Azteca. (2021, 24 de febrero). ¿Qué son las buchonas? Emma Coronel y las mujeres de los capos del narco. [Nota de prensa]. https://www.tvazteca.com/aztecanoticias/notas/buchonas-quienes-son-mujeresnarco-emma-coronel-especiales

Torres Torija, M., Saavedra, F. (2019). Las formas de resistencia ante la violencia en Perra Brava de Orfa Alarcón. Altre Modernita: Revista di studi letterari e culturali. Universitá degli studi di Milano, 3. https://dialnet.unirioja.es/servlet/articulo?codigo=7147557

Valencia, S. (2010). Capitalismo gore. Melusina. 